Results are reported from an investigation of the predictive power of three interviewer social status and five personality factors in a multiple regression analysis with four interviewer performance criteria. Personality factors are found to be more predictive of performance than social status. Clearly, one can improve the probability of hiring quality interviewers by collecting and evaluating social status and personality characteristics of applicants.

\title{
SOCIAL STATUS AND PERSONALITY FACTORS IN PREDICTING INTERVIEWER PERFORMANCE
}

\author{
GENE F. SUMMERS \\ Department of Rural Sociology \\ University of Wisconsin (Madison) \\ E. M. BECK \\ Department of Sociology \\ University of Michigan
} research organization. The decision to do so is often motivated by budgetary considerations. Since limited budget projects, which are often one-time operations, do not permit the researcher the luxury of accumulating a pool of interviewers who have demonstrated their qualifications through field performance, the initial selection of high-quality personnel is crucial. For researchers who normally use the services

AUTHORS' NOTE: Support for this research was provided by the Collcge' of Agriculture and Life Sciences at the University' of Wisconsin, Madison, and Public Health Service Research Grant MH.19689 from the National Institute of Mental Health and the Office of Economic Rescarch. Economic Development Administration, Grant OER-417-G-73.7 (99.7.13248).

SOCIOLOGICAL METHODS \& RESEARCH, Vol. 2 No. 1, August 1973 (C) 1973 Sage Publications, Inc. 
of survey research organizations employing trained professional interviewers, there probably is little cause for concern. Yet for the researcher whose budget will not permit the costs of professional services, the success of the research project rests heavily upon the selection of interviewers.

Unfortunately, little research is available to guide the low-budget researcher in the selection of high-quality interviewers. The present study partially alleviates this problem by providing information on the prediction of interviewer performance using as predictors interviewer characteristics which may be easily obtained on personnel application forms. The performance criteria are total activity and refusal rates. We are aware, of course, that these are not the only possible criteria, and, in fact, further research ought to be concerned with accuracy and reliability and even more qualitative aspects that, while not easily measured, should not be forgotten.

\section{PERFORMANCE PREDICTORS}

It is useful to distinguish between two sets of interviewer characteristics: (1) social status, including such factors as age, sex, marital status, or educational attainment; and (2) personality factors, such as assertiveness or anxiety. Several studies demonstrate the importance of these factors for interviewer performance. In a study of response error Lansing, et al. (1961) found there was reason to believe that interviewer anxiety was directly related to interview response rates. In Richardson's study of interviewers, it was concluded that the most desirable interviewers were middle-aged females with high education and intelligence and who scored high in human relations, symbolic aggression, affiliation, and intragression on the Thematic Apperception Test (Richardson et al., 1965: 275-276, 277-280). Hauck and Steinkamp (1964) found that interview response rates were not differentiated 
by the age or sex of the interviewer whether or not the interviewer was married, or by any other demographic factor. Yet, utilizing a stepwise regression procedure, they isolated two major variables affecting interviewer success: (1) the self-confidence of the interviewer and (2) the interviewer's dominance score on the Edwards Personal Preference Schedule. These two factors, combined with the number of hours per week the interviewer could work, accounted for $71 \%$ of the variance in interviewer success. Sudman's (1967) study of NORC interviewers shows that high-quality interviewers tend to be well educated, intelligent, manifest a need for achievement, have a career orientation, and enjoy the interview activity.

These studies demonstrate the value of using both social status and personality factors to predict interviewer performance. This paper will present the results of an investigation into the predictive power of three social status and five personality factors in a multiple regression analysis with four performance criteria. At this juncture, a brief caveat is in order. The number of interviewers studied is small $(n=23)$; the respondents were all small-town and rural residents and mostly male; and the interviewers were local school teachers. In short, these data are from a unique field survey situation.

\section{PROCEDURES}

In spring, 1971, a research team from the University of Wisconsin began preparing for the collection of survey data from an area probability sample of heads of households in two rural regions of Illinois. This collection was the final field operation of a five-year study of the impact of industrial development in one of these rural areas (for a more complete discussion of the research project, see Summers et al., 1969). Interviews followed a structured schedule which took approximately 45 minutes to administer. Based on previous 
experience with local public school teachers as interviewers, an effort was made to solicit applications from teachers in each region. After an individual screening of applicants, ${ }^{1} 23$ teachers were hired as interviewers. All were residents of the community in which they were to conduct interviews and were Caucasian. Forty-eight percent were male, $78 \%$ were married, and their mean age was 32.61 years. During the interval between hiring and the interviewer training sessions (several weeks), each interviewer completed a short test of personality, The Behavioral Self-Rating (BSR) Form (Borgatta, 1964).

At the conclusion of field operations, the performance of each interviewer was tabulated. The mean number of housing units assigned was 51.6, while the mean number of successful interviews was 41.91 per interviewer, and there was an average of 5.70 refusals for each interviewer (see Table 1.)

Four interviewer performance criterion variables were defined: ${ }^{2}$

(1) the total number of housing units interviewed;

(2) the total number of housing units refusing interviews;

(3) the relative number of housing units interviewed-i.e.,

$$
\text { Interview rate }=\frac{\text { Number of Housing Units Interviewed }}{\text { Number of Housing Units Assigned }} \text {; and }
$$

(4) the relative number of refusals-i.e.,

$$
\text { Refusal rate }=\frac{\text { Number of Housing Units Refused }}{\text { Number of Housing Units Assigned }} .
$$

In considering these performance criteria, one should note that some assigned housing units were returned by interviewers for reasons other than completion of an interview or refusal. Such reasons included noncontact, hospitalization of the household head, and physical inability of the head to 
respond to questions. Thus, there is not an artifactually created dependence between criteria 1 and 2 or between 3 and 4.

Eight variables were used to predict interviewer performance on each of the four criterion variables. Three social status predictors were included: (1) sex, (2) marital status, and (3) age. $^{3}$ Education was not included since all interviewers were college graduates. These measures were obtained on the interviewer's application form. The personality predictors were the five subscales of the Borgatta BSR personality test: (1) Assertiveness, (2) Likeability, (3) Intelligence, (4) Emotionality, and (5) Responsibility. Each of the subscale scores is the summation of four self-ratings on a 10-point, 0-9, choice range. Although this is indeed a very short test of personality, cross-validation of the instrument shows it to have a remarkably stable structure with satisfactory subscale internal consistency reliability coefficents (Freeman and Simons, 1963; Borgatta, 1964; Summers et al., 1971).

\section{FINDINGS}

In any study designed to predict performance, three criteria are uppermost in importance. First, the predictor variables should jointly account for a substantial proportion of the variance in the criterion variables. Second, each predictor variable should contribute to the explained variance in the criterion variables. And finally, predictor variables should discriminate; i.e., their pattern of relationship with "success" criteria should be reversed for "failure" criteria.

The intercorrelations of social status, personality and performance criterion variables are presented in Table 1 with means and standard deviations. While our primary concern is the regression of the criterion variables on status and personality factors, it is worthwhile to note some things in 


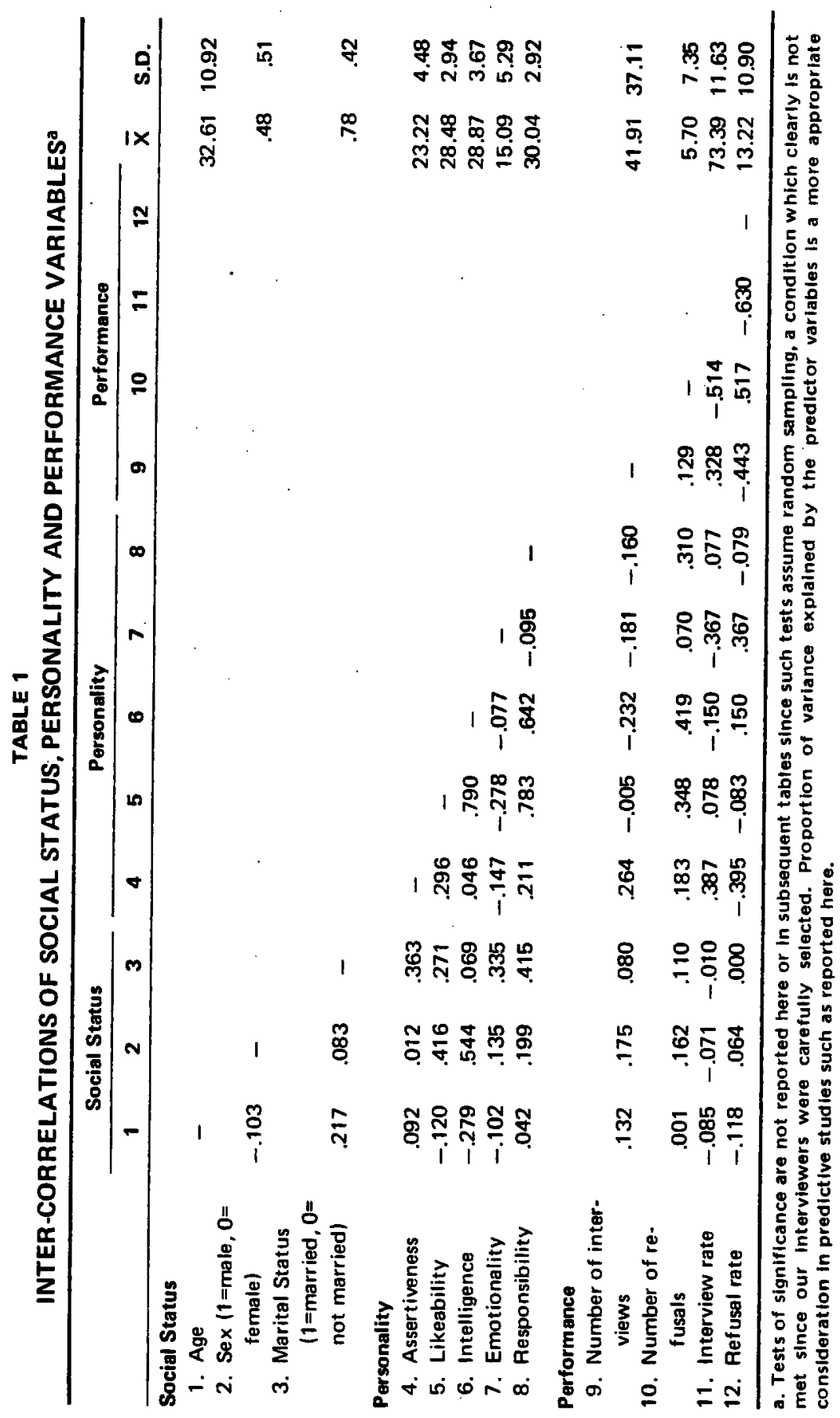

[116] 
the correlation matrix. With minor exceptions, the intercorrelations among the predictor variables are relatively low, which is desirable since one wishes each to contribute to the explained variance in the criterion variables and strong correlations would act as an impediment. The intercorrelations among the BSR subscale scores follow the pattern reported by Borgatta (1964) and Summers et al. (1971). While there is a substantial correlation between Intelligence and Responsibility and between these and Likeability, there is sufficient reliable variance within each cluster of items (subscale score) to warrant consideration of each as a predictor variable. The zero order correlation between predictor and criterion variables is generally low to moderate. Given the relationships among predictor variables this is an acceptable situation, since it permits an additive effect of the predictor variables to operate in the multiple regression.

Table 2 presents the standardized and unstandardized regression coefficients of each of the criterion variables on the predictor variables. Use of the standardized coefficients greatly facilitates the evaluation of the relative importance of each of the predictor factors.

Taking the number of interviews as the criterion, it can be seen that neither the marital status nor the age of the interviewer have much influence on this criterion. The degree of assertiveness, emotionality, and responsibility are only marginally important in affecting the number of housing units interviewed. The most important predictor of the volume of interviews is the interviewer's perception of his own intelligence, which is negatively associated with this criterion of performance. Likeability and interviewer's sex are also important predictors: both of these variables have a positive influence on the number of housing units interviewed. The eight predictors account for $34.77 \%$ of the variance in the total number of housing units interviewed.

When the absolute number of housing units refusing to be interviewed is taken as the criterion, it is seen that the 
[118] SOCIOLOGICAL METHODS \& RESEARCH

TABLE 2

UNSTANDARDIZED AND STANDARDIZED REGRESSION COEFFICIENTS $(n=23)$

\begin{tabular}{lcccc}
\hline & \multicolumn{4}{c}{ Criterion Variable } \\
\cline { 2 - 5 } Predictor Variable & $\begin{array}{c}\text { Number of } \\
\text { Interviows }\end{array}$ & $\begin{array}{c}\text { Number of } \\
\text { Refusals }\end{array}$ & $\begin{array}{c}\text { Interview } \\
\text { Rate }\end{array}$ & $\begin{array}{c}\text { Refusal } \\
\text { Rate }\end{array}$ \\
\hline Intercept & 156.210 & -41.598 & .926 & -0.263 \\
Sex & 32.769 & -2.406 & 0.055 & -0.040 \\
& $(0.451)^{\mathrm{a}}$ & $(-0.167)$ & 0.241 & $(-0.186)$ \\
Marital Status & 8.183 & -1.832 & -0.014 & 0.019 \\
& $(0.093)$ & $(-0.105)$ & $(-0.052)$ & $(0.073)$ \\
Age & -.058 & 0.119 & -0.003 & 0.002 \\
& $(-.017)$ & $(0.177)$ & $(-0.321)$ & $(0.151)$ \\
Assertiveness & 1.361 & 0.330 & 0.009 & -0.002 \\
Likeability & $(0.164)$ & $(0.201)$ & $(0.352)$ & $(-0.088)$ \\
& 4.135 & 0.239 & -0.006 & -0.002 \\
Intelligence & $(0.327)$ & $(0.096)$ & $(-0.158)$ & $(-0.043)$ \\
& -6.648 & 1.082 & -0.018 & 0.026 \\
Emotionality & $(-0.658)$ & $(0.540)$ & $(-0.574)$ & $(0.889)$ \\
& -1.589 & 0.330 & -0.009 & 0.007 \\
Responsibility & $(-0.227)$ & $(0.237)$ & $(-0.410)$ & $(0.361)$ \\
& -2.261 & -0.156 & .018 & -0.014 \\
& $(-0.178)$ & $(-0.062)$ & $(0.443)$ & $(-0.385)$ \\
\% Variance Explained & $34.77^{b}$ & 25.57 & 40.50 & 42.31 \\
\hline
\end{tabular}

a. Standardized coefficients.

b. Uncorrected for degrees of freedom.

interviewer's perceived Intelligence is again the most important predictor: this time, however, its effect is positive. There is also a moderately positive contribution of Emotionality and Assertiveness to the number of refusals. Although interviewer's age and sex seem to have some small impact on the number of refusals, the remainder of the predictors have little influence on this criterion. The explanatory variables' ability to account for the variance in the number of refusals is diminished substantially: we can attribute only $25.57 \%$ of the variance in the number of refusals to our predictors. 
Thus, considering volume of completed interviews and refusals, unstandardized for number of assignments, we find that Intelligence is the single most important predictor. However, it is negatively associated with the volume of completed interviews and positively associated with refusals. A similar, although weaker, pattern is observed for Emotionality. Likeability and sex manifest a positive contribution to the number of completed interviews and a negative contribution to refusals.

When one controls for the number of housing units assigned to each interviewer by using the interview rate as the criterion, one finds that the interviewer's Intelligence, Emotionality, and Responsibility are the most important predictors of interviewer performance. Note that the former two personality factors are negatively associated with the interview rate, while the latter is positively associated. Assertiveness and sex (being male) also make a moderately positive contribution to interview rate while age acts as a moderately negative influence. Together the three social status and five personality variables account for $40.50 \%$ of the variance in interview rate.

Taking the refusal rate as the criterion, it can be seen that the most important predictor is again Intelligence, and its influence is positive and strong. Indeed, the influence of the other predictors is pale by comparison. There are two other personality variables making a moderate contribution to refusal rates. They are Emotionality, which is positively related to refusal rates, and Responsibility, which is negatively associated. Thus, it appears that self-attribution of intelligence and emotionality contribute independently to higher refusal rates while responsibility offsets these effects to some degree. Jointly, the predictor variables explain $42.31 \%$ of the variance in the refusal rates.

Table 3 gives the percentage of total variance for each criterion of performance that is attributable to the social status set of variables and the personality set. The social 
TABLE 3

PERCENTAGE OF TOTAL VARIANCE DUE TO GROUPS OF PREDICTOR VARIABLES

\begin{tabular}{lccc}
\hline Criterion Variable & $\begin{array}{c}\text { Due to Social } \\
\text { Status Variables }\end{array}$ & $\begin{array}{c}\text { Due to Personality } \\
\text { Variables }\end{array}$ & $\begin{array}{c}\text { Explained } \\
\text { Variance }\end{array}$ \\
\hline Number of interviews & 5.43 & 29.34 & 34.77 \\
Number of refusals & 3.55 & 22.02 & 25.57 \\
Interview rate & 1.40 & 39.10 & 40.50 \\
Refusal rate & 7.25 & 35.06 & 42.31 \\
\hline
\end{tabular}

a. Uncorrected for degrees of freedom.

status group was entered into the regression first. Thus, the partitioning of the variance would be altered if the personality set had been placed first. This ordering was chosen deliberately to permit the social status variables to absorb as much of the variance in performance criteria as they could before entering personality into the regression. Our rationale for doing so was one of parsimony. Since most researchers who review applicants for interviewer positions already obtain social status data, it would be most parsimonious to find that personality variables do not increment one's predictive power beyond that attributable to social status variables. In view of the advantage which is given thusly to the social status variables, it is most significant that for each criterion of performance the personality factors far outweigh the influence of social status variables.

\section{CONCLUSIONS}

These results lead to several conclusions. First, and perhaps most important to the low-budget researcher, one can improve the probability of hiring quality interviewers by collecting and evaluating social status and personality characteristics of the applicants. Second, the Borgatta Behavioral Self-Rating Form provides a set of personality scores which appear adequate for the purpose of identifying applicants 
who will generate high completion rates and those who likely will have high refusal rates. Third, the personality factors appear to be more important in determining performance criteria than social status variables. Fourth, among the personality variables, Intelligence (perhaps better labelled self-attribution of intelligence) clearly is the most important variable in the prediction of performance. And it is worthy of notice that its relationship to performance is counter-intuitive. The higher regard one has for his (or her) intelligence, the less successful one is likely to be as an interviewer. A similar pattern is observed for self-attribution of emotionality. Conversely, persons who see themselves as assertive and responsible are better risks as interviewers. Finally, with regard to social status variables, one may tentatively conclude that younger males have a slight advantage. Marital status appears to be unrelated to performance as it is measured in these data.

The limitations of small sample size and rural interviewing notwithstanding, the percentage of variance explained and the ease of measuring the predictor variables compel us to conclude that low-budget researchers would be wise to consider personality factors as well as social status characteristics of applicants when hiring interviewers.

\section{NOTES}

1. The initial screening consisted of reviewing application forms and letters of recommendation and a personal interview with Professor Summers. The application form provided information on personal data (age, sex, marital status), work history, length of residence in area, hours available for interviewing, access to automobile, and previous interviewing experience. None of the teachers who were hired had professional survey interviewing experience. However, all had conducted "parent-teacher conferences" in connection with teaching and nearly all had been involved in local data gathering activities such as the annual school census.

2. Number of Housing Units Assigned $=$ Number of Units Interviewed + Number of Units Refused + Number of Units Returned by the Interviewer for reasons other than refusal or completion of interview. 
3. The following coding conventions were employed: (1) sex: males $=1$, females $=0$ and (2) marital status: married $=1$, not married $=0$.

\section{REFERENCES}

BORGATTA, E. F. (1964) "A very short test of personality: the Behavioral Self-Rating (BSR) Form." Psych. Reports 14: 275-284.

FREEMAN, H. E. and O. G. SIMMONS (1963) The Mental Patient Comes Home. New York: John Wiley.

HAUCK, M. and S. STEINKAMP (1964) "Survey reliability and interviewer competence." University of Illinois Bureau of Economic and Business Research Studies in Consumer Savings 4.

LANSING, J. B., G. P. GINSBURG, and K. BRAATEN (1961) "An investigation of response error." University of Illinois Bureau of Economic and Business Research Studies in Consumer Savings 2.

RICHARDSON, S. A., B. S. DOHRENWEND, and D. KLEIN (1965) Interviewing: Its Forms and Functions. New York: Basic Books.

SUDMAN, S. (1967) Reducing the Cost of Surveys. Chicago: Aldine.

SUMMERS, G. F., M. BURKE, S. SALTIEL, and J. P. CLARK (1971) "Stability of the structure of work orientations among high school students." Multivariate Behavioral Research 6 (January): 35-50.

SUMMERS, G. F., R. L. HOUGH, J. T. SCOTT, and C. L. FOLSE (1969) "Before industrialization: a rural social system base study." University of Illinois Agriculture Experiment Station Bulletin 736. 